\title{
New Insights Into the Regulation of $\gamma \delta$ T Cells by BTN3A and Other BTN/BTNL in Tumor Immunity
}

\author{
Juan-Luis Blazquez ${ }^{1 \dagger}$, Audrey Benyamine ${ }^{2 t}$, Christine Pasero ${ }^{3 * t}$ and Daniel Olive ${ }^{1,4 *}$ \\ ${ }^{1}$ INSERM, U1068, Centre de Recherche en Cancérologie de Marseille (CRCM), Immunity \& Cancer, Institut Paoli-Calmettes; \\ Aix-Marseille Université UM105, CNRS UMR 7258, Marseille, France, ${ }^{2}$ Aix-Marseille Université (AMU), Médecine Interne \\ Hôpital Nord, Assistance Publique Hôpitaux de Marseille (AP-HM), Marseille, France, ${ }^{3}$ Imcheck Therapeutics, Marseille, \\ France, ${ }^{4}$ Immunomonitoring platform, Institut Paoli-Calmettes, Marseille, France
}

OPEN ACCESS

Edited by:

Kenth Gustafsson,

University College London,

United Kingdom

Reviewed by:

Ashutosh Chaudhry,

Memorial Sloan Kettering

Cancer Center, United States

Cosima T. Baldari,

University of Siena, Italy

Laura Patrussi contributed to the

review of Cosima T. Baldari

*Correspondence:

Christine Pasero

christine.pasero@imcheck.fr;

Daniel Olive

daniel.olive@inserm.fr

tThese authors have contributed equally to this work.

Specialty section: This article was submitted to T Cell Biology,

a section of the journal

Frontiers in Immunology

Received: 15 March 2018 Accepted: 27 June 2018

Published: 11 July 2018

Citation:

Blazquez J-L, Benyamine A, Pasero C and Olive D (2018) New

Insights Into the Regulation of $\gamma \delta$ T Cells by BTN3A and Other BTN/BTNL in Tumor Immunity.

Front. Immunol. 9:1601. doi: 10.3389/fimmu.2018.01601
Recent findings in the immunology field have pointed out the emergent role of butyrophilins/butyrophilin-like molecules (BTN/BTNL in human, Btn/Btnl in mouse) in the modulation of $\gamma \delta$ T cells. As long as the field develops exponentially, new relationships between certain $\gamma \delta T$ cell subsets, on one hand, and their BTN/BTNL counterparts mainly present on epithelial and tumor cells, on the other, are described in the scientific literature. Btnl1/Btnl6 in mice and BTNL3/BTNL8 in humans regulate the homing and maturation of $V \gamma 7+$ and $V \gamma 4+T$ cells to the gut epithelium. Similarly, Skint-1 has shown to shape the dendritic epidermal $T$ cells repertoire and their activation levels in mice. We and others have identified BTN3A proteins are the key mediators of phosphoantigen sensing by human $V_{\gamma} 9 \mathrm{~V} \delta 2 \mathrm{~T}$ cells. Here, we first synthesize the modulation of specific $\gamma \delta T$ cell subsets by related BTN/BTNL molecules, in human and mice. Then, we focus on the role of BTN3A in the activation of $V_{\gamma} 9 \mathrm{~V} \delta 2 \mathrm{~T}$ cells, and we highlight the recent advances in the understanding of the expression, regulation, and function of BTN3A in tumor immunity. Hence, recent studies demonstrated that several signals induced by cancer cells or their microenvironment can regulate the expression of BTN3A. Moreover, antibodies targeting BTN3A have shown in vitro and in vivo efficacy in human tumors such as acute myeloid leukemia or pancreatic cancer. We thus finally discuss how these findings could help develop novel $\gamma \delta \mathrm{T}$ cell-based immunotherapeutical approaches.

Keywords: $\gamma \delta$ T cells, butyrophilins, BTN3A, tumor immunity, immunotherapy

\section{$\gamma \delta$ T CELL SUBSETS AND RELATED BTN/BTNL PROTEINS}

\section{$\gamma \delta$ T Cell Subsets}

Arising from the same common multipotent double negative precursor than the $\alpha \beta \mathrm{T}$ cells, and differentiated earlier in the thymus, $\gamma \delta \mathrm{T}$ cells comprise a heterogeneous group of cells that are considered to be a link between innate and adaptive immunity.

The main characteristic that defines the $\gamma \delta$ T cells is the expression of its distinctive TCR composed by a $\gamma$-chain and a $\delta$-chain, that is called $\gamma \delta$ TCR. In humans, $0.5-16 \%$ of all CD $3+$ cells in adult peripheral blood and organized lymphoid tissues (thymus, spleen, tonsil, and lymph nodes) are $\gamma \delta \mathrm{T}$ cells, they usually represent less than $5 \%$ in tongue and reproductive tract and $10-30 \%$ in intestine $(1,2)$. In adult mice, $1-4 \%$ of the entire $\mathrm{T}$ cell compartment in thymus, secondary lymphoid organs and lung are $\gamma \delta \mathrm{T}$ cells. Higher numbers of $\gamma \delta \mathrm{T}$ cells are found in other mucosal sites, reaching until $10-20 \%$ of all T cells in female reproductive organs (3), $20-40 \%$ of the intestinal intraepithelial T cells (4), and $50-70 \%$ of skin dermal T cells $(2,5,6)$. 
Like B cells and $\alpha \beta$ T cells, $\gamma \delta$ T cells have an RAG-mediated rearranged antigen receptor by the combination of $\mathrm{V}$ (variable), $\mathrm{D}$ (diversity), and J (joining) gene segments. In human, there are only a few $\mathrm{V} \gamma(\mathrm{V} \gamma 2,3,4,5,8,9)$ and $\mathrm{V} \delta(\mathrm{V} \delta$ 1,2,3,4,6,7,8) germline genes that can be used to rearrange (7). Nonetheless, the CDR3 loop of V $\delta$-chain shows a high degree of diversity thanks to multiple $\mathrm{D}$ gene segments. In addition, the insertion or loss of $\mathrm{N}$-nucleotides during the junctional diversification process further enriches this diversity (8). Available $\mathrm{V} \gamma$ and $\mathrm{V} \delta$ genes are not randomly used. Thus, certain $\mathrm{V} \delta$ chains tend to pair almost exclusively with another $\mathrm{V} \gamma$ chain (like $\mathrm{V} \gamma 9$ and $\mathrm{V} \delta 2$ in humans), and some $\gamma \delta$ T cells expressing certain $\mathrm{V} \gamma$ and $\mathrm{V} \delta$ genes preferentially reside in well-defined tissue locations (Table 1).

In contrast to conventional $\alpha \beta$ T cells, the antigen recognition mechanism in $\gamma \delta$ T cells is not MHC-restricted. Indeed, $\gamma \delta$ T cells seem to be implicated in the recognition of different antigens than $\alpha \beta$ T cells. While $\alpha \beta$ T cells recognize non-self-peptide fragments restricted by $\mathrm{MHC}$ molecules, $\gamma \delta \mathrm{T}$ cells can recognize unconventional antigens as stress molecules (MICA and MICB), non-peptidic metabolites of isoprenoid biosynthesis, heat-shock proteins, and so on (12).

As cytotoxic CD8+ T cells do, $\gamma \delta \mathrm{T}$ cells can elicit a broad cytotoxic activity against infected and transformed cells. This cytotoxic activity is based on death receptor/ligand (Fas/FasL) signals and perforin/granzyme to destabilize cellular integrity (12). $\gamma \delta$ T cells also secrete various cytokines (16) and chemokines including proinflammatory Th1-like cytokines such as IFN- $\gamma$ and TNF- $\alpha$ in order to activate several immune mediators (dendritic cells and Th1), arrest proliferation, and kill target cells (17). Thanks to these cytotoxic properties, $\gamma \delta$ T cells highlight among other immune mediators, along with $\mathrm{CD} 8+\mathrm{T}$ and NK cells, as a powerful tool for cancer immunotherapy.

\section{The BTN/BTNL Protein Families}

The butyrophilins (BTN) and butyrophilin-like (BTNL) genes are part of the immunoglobulin superfamily. They are structurally related to the $\mathrm{B} 7$ proteins, which comprise co-stimulatory (B7-1, ICOS, etc.) and co-inhibitory (PD-L1, PD-L2, B7-H3, etc.) molecules involved on $\mathrm{T}$ lymphocytes regulation. The seven human BTN genes are clustered in the MHC class I region of chromosome $6(18,19)$ into three phylogenetically related subfamilies: BTN1, BTN2, and BTN3, in humans. The BTN1 subfamily consists only in the BTN1A1 gene, whereas the BTN2 and BTN3 subfamilies have three genes: BTN2A1, BTN2A2, and BTN2A3 pseudogene, and BTN3A1, BTN3A2, and BTN3A3. The BTN proteins show high structural homology, with BTN1, BTN2, and BTN3 subfamilies sharing the $50 \%$ of their amino acid identity. The homology between the BTN2 and BTN3 is even closer, reaching on average $80 \%$ identity (20). The high homology rates observed suggest that the BTN genes have undergone tandem duplication. Although further, the BTNL family still shares considerable homology (on average $40 \%$ identity) to the BTN-family members. Five identified BTNL genes are encoded in the human genome. BTNL2, the best-known member of this family, is clustered with the BTN genes in the MHC class I region of chromosome 6 , while the chromosome 5 harbors the coding sequences of BTNL3, BTNL8, and BTNL9. The genomic sequence of SKINTL pseudogene is found in the chromosome 1.

In the mouse genome, however, only two Btn proteins are found: Btn1a1, who plays a role in the regulation of milk fat globule secretion (21), and Btn2a2. Both genes are clustered on chromosome 13, and are orthologs of human BTN1A1 and BTN2A2, respectively. Eight different murine Btnl genes have been described so far (Btnl1, 2, 4, 5, 6, 7, 9 and skint-1). Two of them are predicted to be pseudogenes (Btnl5 and Btnl7). Six of them are located in the same genomic region, at the MHC class II locus (chromosome 17), while Btnl9 is the only Btnl gene found on chromosome 11, whereas the Skint-1 (Figure 1) gene is encountered on chromosome 4. Given their high extracellular identity, Btnl9 and Btnl2 are thought to be orthologs of human BTNL molecules. Recent advances in the field have pointed out the role of BTN3, Skint-1, Bntl1/Btnl6, and BTNL3/BTNL8 as key immune regulators of $\gamma \delta \mathrm{T}$ cells in humans and mice (Figure 1) (22-26).

\section{REGULATION OF SPECIFIC $\gamma \delta$ T CELL SUBSETS BY BTN/BTNL PROTEINS}

\section{Skint-1 and Dendritic Epidermal T Cells (DETCs)}

The study of the $\mathrm{T}$ cell repertoire in mice with a Skint-1-/genetic background pointed out the relevance of the interaction

TABLE $1 \mid \gamma \delta$ T cell subsets and tissue locations in human and mouse.

\begin{tabular}{|c|c|c|c|c|}
\hline Species & V gene segment pairing & V(D)J diversity & Tissue location & References \\
\hline & Vy9V82-T cells & Intermediate & Main peripheral blood $\gamma \delta \mathrm{T}$ population (paired with $\vee_{\gamma} 9$ ) & $(9,11)$ \\
\hline & V83-T cells & High & Liver, higher numbers in chronic viral infections and leukemia, gut epithelia & $(9,10,12)$ \\
\hline & 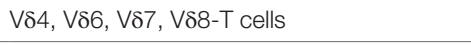 & & Peripheral blood of lymphoma patients & $(13)$ \\
\hline \multirow[t]{6}{*}{ Mouse } & $V_{\gamma 1} 1 N_{\gamma} 4 \gamma \delta-T$ cells & High & Predominant in spleen & (14) \\
\hline & Vy7-T cells & Intermediate & Gut epithelia (paired with $\vee \delta 4, \vee \delta 5$, and V86) & (14) \\
\hline & Vy5V81-T cells (dendritic epidermal T cells) & Invariant & Major subset in mice skin & (15) \\
\hline & Diverse & High & Adult thymus & (10) \\
\hline & Diverse & High & Lymph node & (10) \\
\hline & $V_{\gamma} 1 V_{\delta} 6 / 3, V_{\gamma} 4$ and $V_{\gamma} 6-T$ cells & Intermediate & Liver & (10) \\
\hline
\end{tabular}




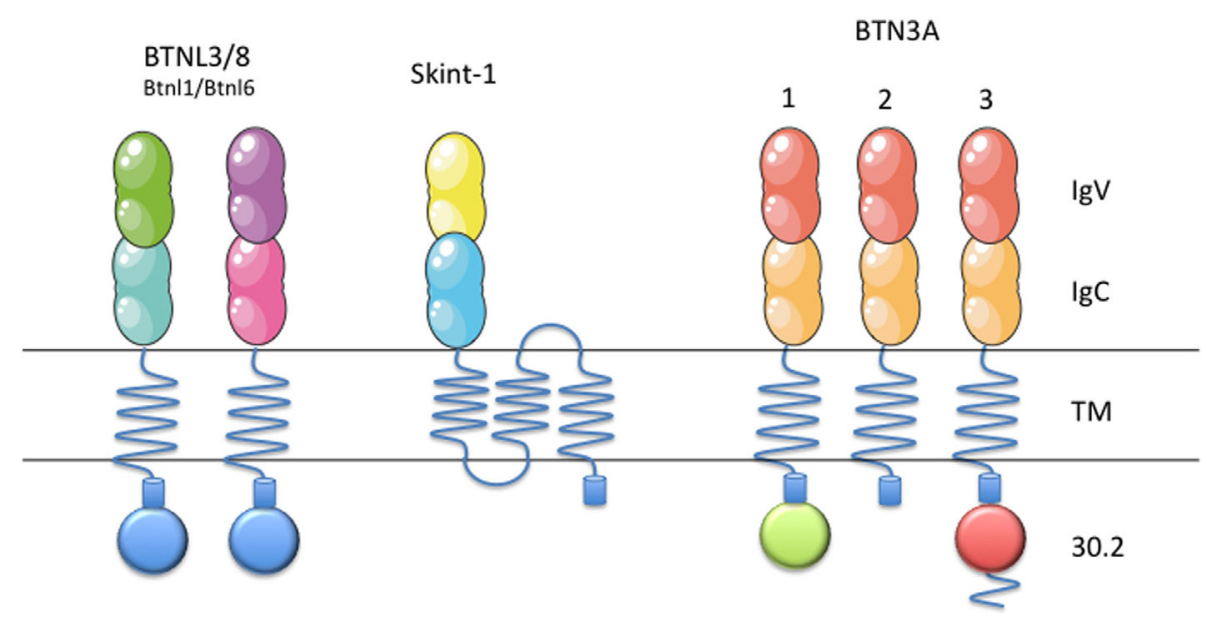

FIGURE 1 | Schematic representation of BTN3, Btnl1, Btnl6, BTNL3, BTNL8, and Skint-1. Schematic representation of BTN/BTNL molecules in mice (Btnl1, Btnl6, and Skint-1) and humans (BTN3, BTNL3, and BTNL8), that have been shown to regulate specific $\gamma \delta$ T cell subsets. Each subfamily member contains an extracellular, $\mathrm{N}$-terminal IgV, and a membrane-proximal IgC domain connected to a single-pass transmembrane domain. BTN3A1 and BTN3A3 contain intracellular B30.2 domains, as well as BTNL3 and BTNL8, which is missing in BTN3A2. This figure was created in part using graphics from Servier Medical Art (https://smart. servier.com/) with permission.

between Btn/Btnl proteins and $\gamma \delta \mathrm{T}$ cells, as these mice do not develop canonical V $\gamma 5 \mathrm{~V} \delta 1+\operatorname{DETCs}(27,28)$. Skint- 1 is a transmembrane protein without any known ortholog in humans (Figure 1), but it shows a high degree of homology with a subfamily of BTNL molecules, which are conserved in humans $(25,29,30)$. Skint-1 is expressed at detectable levels exclusively by keratinocytes and thymic epithelial cells, where it promotes the IFN- $\gamma$ production and TCR hyporesponsiveness of DETC progenitors (Figure 2) $(31,32)$. Mature DETCs exist in a semiactivated state under homeostatic conditions. This activation is explained, at least in part, by a constitutive TCR engagement through ligand recognition on surrounding keratinocytes within this tissue in vivo (33). Nevertheless, while a DETC TCR ligand was expressed on the surface of keratinocytes at the wound edge in FVB-Tac mice (a substrain of FVB mice, harboring a mutation in Skint-1, specifically deficient for Vy5V81 DETCs), Skint-1 was not able to directly bind the DETC TCR, neither detected on the surface of keratinocytes $(19,25,31)$. Thus, although Skint-1 expression is fundamental for the development of canonical V $\gamma 5 \mathrm{~V} \delta 1+$ DETCs, the underlying mechanisms by which Skint-1 promotes the maturation of these cells remain poorly understood. However, DETC tetramers did inhibit wound closure in vivo (34) suggesting that Skint-1 might not be the ligand, or at least the only ligand, of the DETC TCR in keratinocytes. It has to be noted that direct binding between $\gamma \delta$ TCRs and any Btn/Btnl has not been described so far in the scientific literature.

Intriguingly, Skint-1 was not readily expressed at the cell surface of HEK293 cells transfected with WT Skint-1 (28). This finding suggests that an accessory protein might help Skint-1 to properly localize at the cell membrane compartment. Unfortunately, this accessory protein has not been identified so far.

\section{Btnl1/Btnl6 and $V_{\gamma} 7+$ IELs in Mice, BTNL3/ BTNL8 and $V \gamma 7+$ IELs in Humans}

In mice, several Btnl proteins are only expressed at protein level in the intestinal epithelium, concretely on enterocytes of the small-intestinal villus epithelial cells $(25,26)$. In this way, the expression of Btnl1 by small-intestinal villi at an early time point in life was recently found to critically and selectively promote $\mathrm{V} \gamma 7+$ intraepithelial lymphocytes (IELs) maturation and expansion within the tissue (Figure 2) (26). The first evidence came from the study of IEL populations on four different strains of Btnl1-/- mice, where V $\gamma 7+$ IEL numbers were depleted by $\sim 90 \%$, with $\mathrm{V} \gamma 7+\mathrm{V} \delta 4+$ cells almost ablated. The specificity of the interaction between V $\gamma 7+$ IELs and Btnll was emphasized by the fact that Btnl4-/- mice displayed no overt defects in any major IEL subset.

In 2016, Lebrero-Fernandez et al. reported an enhancement on cell surface expression of Btnl1 on Btnl1-transfected MODE-K cells when these cells were concomitantly transfected with Btnl4 and Btnl6 (35). In the same way, Btnll greatly enhanced the expression of Btnl6 on the cell surface in vitro (26). Conversely, co-transfecting Btnl1 or Btnl6 did not augment the cell surface expression of Btnl4. These results match with the fact that Btnl4-/- mice displayed no overt defects in any major IEL subset.

V $77+$ IELs co-cultured with MODE-K stably expressing Btnl1+ Btnl6 cells overexpress the T cell activation marker CD25, downregulate the TCR and CD122 expression levels and show higher levels of granulocyte-macrophage colony-stimulating factor, CCL4, and IFN- $\gamma$ in vitro (26). Likewise, it was observed that human gut epithelial cells as well express BTNL3 and BTNL8, and that concomitant expression of BTNL3 + BTNL8 induces selective TCR-dependent responses of human colonic $\mathrm{V} \gamma 4+$ 


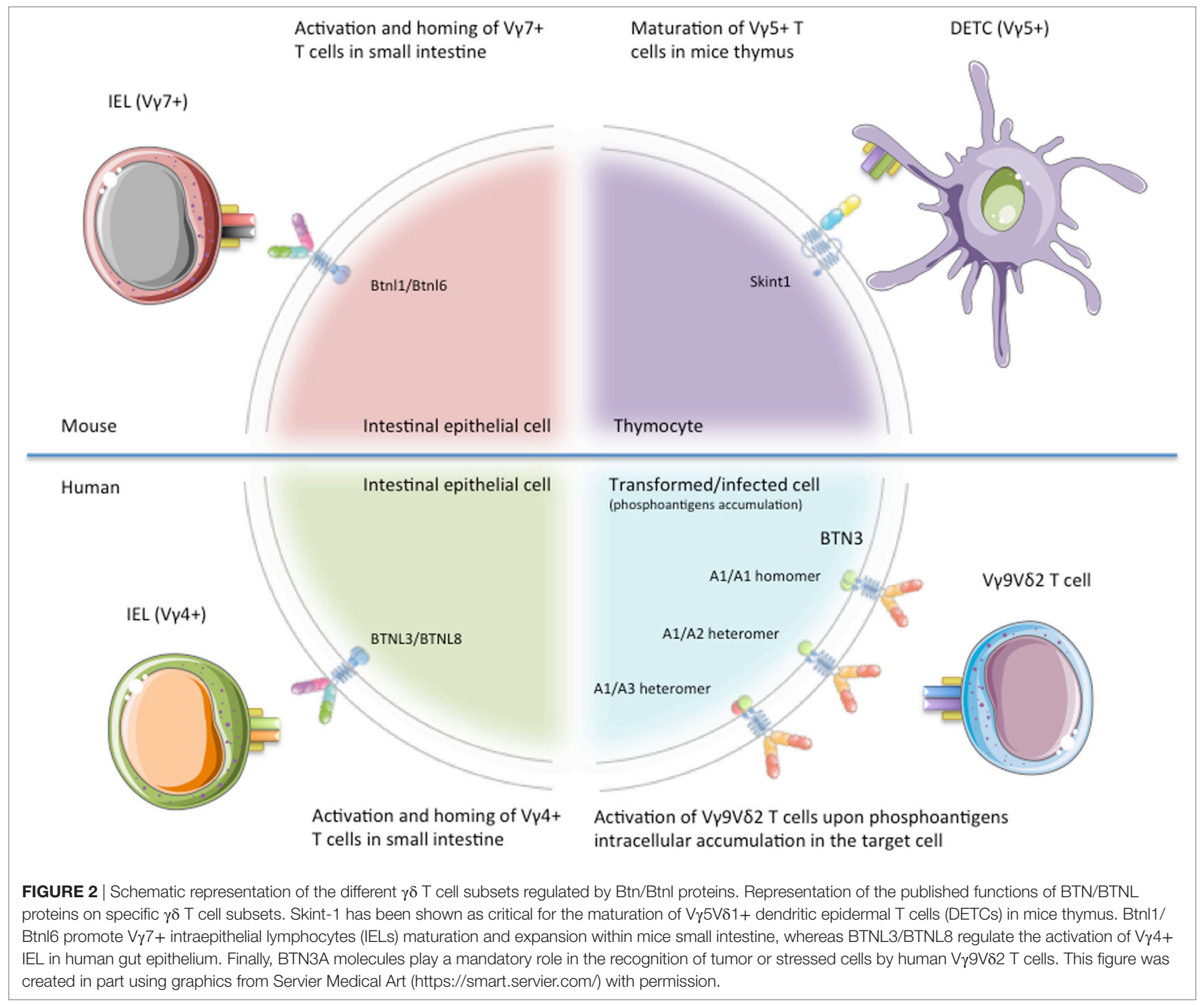

cells (Figure 2) (26). When HEK293 cells were transfected with BTNL3, BTNL8, or BTNL3 + BTNL8, only V82- cells co-cultured with HEK293 cells co-expressing BTNL3+ BTNL8 undergo a marked TCR downregulation (26). Among all the $\gamma \delta \mathrm{T}$ cell subsets included on the V $\delta 2-$ population, only those expressing V $\gamma 4$ effectively downregulated TCRs in co-cultures with L3 + L8 cells. Similar to Skint-1, investigations have failed to report direct $\gamma \delta$ IEL-TCR-BTNL molecule interactions up to date. As for BTNL1 and BTNL6 described above, neither BTNL3 nor BTNL8 protein was efficiently expressed on cells transfected with their respective genes, unless both were co-expressed (36).

\section{V $\gamma 9 \mathrm{~V} \delta 2 \mathrm{~T}$ Cells and BTN3A Proteins}

Due to the pairing restrictions observed in the formation of the $\gamma \delta$ TCR, the V $\delta 2$ chain can be combined almost exclusively with $\mathrm{V} \gamma 9$ forming the $\mathrm{V} \gamma 9 \mathrm{~V} \delta 2-\mathrm{TCR}$. V $\gamma 9 \mathrm{~V} \delta 2 \mathrm{~T}$ cells represent the major $\gamma \delta \mathrm{T}$ cell subset in the human peripheral blood, with values ranging from 50 to $95 \%$ of $\gamma \delta$ T cells. These immune mediators, which have been only found in humans and non-human primates and are evolutionarily conserved in selected species like alpaca (Vicugna pacos) (37), stand out as having the capacity to "sense" several infected and malignant cells. This Vy9V82 T cell reactivity has been associated with intracellular accumulation of organic pyrophosphate-containing molecules, also called phosphoantigens (pAgs) (38). These molecules can be produced by microbes, such as hydroxy-methyl-butyl-pyrophosphate (HDMAPP, also known as HMBPP), a microbial intermediate of the 2-C-methyl-D-erythritol 4-phosphate (MEP) pathway or can be synthetized endogenously, such as isopentenyl pyrophosphate (IPP), an intermediate of the mevalonate pathway in mammal cells that can accumulate in transformed cells during tumorigenesis (39).

After these findings, nitrogen-containing bisphosphonates (N-BPs) like Zoledronic acid have emerged as drugs that, indeed, can raise up the intracellular levels of IPP by the inhibition of farnesyl diphosphate synthase (FPPS) $(40,41)$, thus facilitating 
the activation of human $\mathrm{V} \gamma 9 \mathrm{~V} \delta 2 \mathrm{~T}$ cells against tumor cells. In the same way, several synthetic analogs of HMBPP-like bromohydrin pyrophosphate (BrHPP) have been synthetized up to date, showing all of them potent stimulation of $\mathrm{V} \gamma 9 \mathrm{~V} \delta 2 \mathrm{~T}$ cells (42).

Although the V $\gamma 9 \mathrm{~V} \delta 2-\mathrm{TCR}$ of $\mathrm{V} \gamma 9 \mathrm{~V} \delta 2 \mathrm{~T}$ cells is sufficient for pAg recognition (38), the cell-cell contact is mandatory for the proper $\mathrm{V} \gamma 9 \mathrm{~V} \delta 2 \mathrm{~T}$ cell activation against cancer cells [although some pAgs, like BrHPP can activate V $\gamma 9 \mathrm{~V} \delta 2 \mathrm{~T}$ cells without necessity of cell-cell contact $(43,44)]$, suggesting the presence of a "pAg presenter molecule" in target cells. In addition, none non-primate cell can stimulate the Vy9V $82 \mathrm{~T}$ cells (45), indicating that this antigen-presenting molecule (APM) is characteristic of primates (like $\mathrm{V} \gamma 9 \mathrm{~V} \delta 2 \mathrm{~T}$ cells). On the other side, $\mathrm{V} \gamma 9 \mathrm{~V} \delta 2 \mathrm{~T}$ cell activation relies on the expression of the V 79 V82-TCR as Jurkat cells became reactive against pAgs intracellular accumulation in their targets when they were transfected with V $\gamma 9$ V82-TCR (46). Finally, Harly and coworkers demonstrated the role of the butyrophilin-3A (BTN3A, also called CD277) subfamily of proteins as key mediators of pAg signaling (47).

The second part of this review will be focused on the peculiar antigenic activation process of human $\mathrm{V} \gamma 9 \mathrm{~V} \delta 2 \mathrm{~T}$ cells through BTN3A proteins, and consequently on the mechanism of tumor cell recognition by $\mathrm{V} \gamma 9 \mathrm{~V} \delta 2 \mathrm{~T}$ cells. Recent publications have shed new light on the mode of action of BTN3A.

\section{FOCUS ON BTN3A ROLE ON THE ACTIVATION PROCESS OF HUMAN V $\gamma$ 9V82 T CELLS}

\section{BTN3A1/A2/A3 Isoforms}

Due to the recent discovery of these proteins, most concepts about these molecules remain still obscure. BTN3A subfamily of molecules belongs to the $\mathrm{B} 7 \mathrm{co}$-stimulatory family of molecules. BTN3A subfamily is composed by three members in humans: BTN3A1, BTN3A2, and BTN3A3 (Figure 1) (18). They exhibit 95\% identity between them in their extracellular part, thus forming a monophylogenetic group along with the BT-related members (48). Each subfamily member contains an extracellular, $\mathrm{N}$-terminal $\operatorname{IgV}$, and a membrane-proximal IgC domain connected to a single-pass transmembrane domain. BTN3A1 and BTN3A3 both contain an intracellular B30.2 domain, which is not found in BTN3A2. After its B30.2 domain, BTN3A3 has a unique cytoplasmic tail of 70 amino acids.

All the three isoforms, BTN3A1, BTN3A2, and BTN3A3, after treatment with the 20.1 agonist monoclonal antibody (mAb) can stimulate $\mathrm{V} \gamma 9 \mathrm{~V} \delta 2 \mathrm{~T}$ cells, thus activating them through mechanisms involving decreased mobility (47) and a multimerization of BTN3A molecules (49). These findings suggest the involvement of their extracellular domains in the activation process. Nonetheless, only the BTN3A1 isoform, and to a much lesser extent BTN3A3, can trigger the activation of $\mathrm{V} \gamma 9 \mathrm{~V} \delta 2 \mathrm{~T}$ cells upon phosphoantigen burst (47).

The way BTN3A1 presents pAgs to $\mathrm{V} \gamma 9 \mathrm{~V} \delta 2 \mathrm{~T}$ cells has remained controversial over the last years. The receptor for BTN3A, similar to the receptor for other BTNs or B7-H4, remains to be identified. The very first model of pAgs presentation hypothesized that BTN3A might present pAgs directly to $\mathrm{V} \gamma 9 \mathrm{~V} \delta 2$ $\mathrm{T}$ cells via its extracellular IgV domain (50). This model fails to explain why BTN3A2 is unable to activate $\mathrm{V} \gamma 9 \mathrm{~V} \delta 2 \mathrm{~T}$ cells, taking into account that the $\operatorname{IgV}$ domains of BTN3A1 and BTN3A2 share the $95 \%$ of their amino acid sequence. However, the binding of pAgs to the BTN3A IgV domain was not confirmed by other groups. Harly and coworkers pointed out the importance of the B30.2 intracellular domain of BTN3A1 in the activation process of $\mathrm{V} \gamma 9 \mathrm{~V} \delta 2 \mathrm{~T}$ cells by swapping the B30.2 intracellular domains of BTN3A1 and BTN3A3 (47). Thus, the chimeric BTN3A3 protein carrying the BTN3A1 B30.2 intracellular domain became stimulatory. In fact, the activation levels reached by $\mathrm{V} \gamma 9 \mathrm{~V} \delta 2 \mathrm{~T}$ cells when co-cultured with cells expressing the BTN3A3 chimeric protein were higher than those obtained when V $\gamma 9 \mathrm{~V} \delta 2 \mathrm{~T}$ cells were cultured with cells expressing BTN3A1 WT. Conversely, cells transfected with chimeric BTN3A1 protein carrying the BTN3A3 B30.2 were no longer able to activate $\mathrm{V} \gamma 9 \mathrm{~V} \delta 2 \mathrm{~T}$ cells. Based on these results, a second model for pAgs presentation to $\mathrm{V} \gamma 9 \mathrm{~V} \delta 2 \mathrm{~T}$ cells was proposed. In this model, supported by several articles, BTN3A1 might act as an indirect antigen presentation molecule. Thus, $\mathrm{V} \gamma 9 \mathrm{~V} \delta 2 \mathrm{~T}$ cells would not recognize directly the pAg binding to the $\mathrm{IgV}$ domain of $\mathrm{BTN} 3 \mathrm{~A}$, but they might recognize the conformational changes triggered in BTN3A1 by the binding of pAgs to its B30.2 domain. Even more recent data focusing on the BTN3A1 B30.2 domain show that only the B30.2 intracellular domain of BTN3A1 can directly bind pAg through a positively charged surface pocket under physiological conditions. Several basic residues along this binding pocket including histidines (His351 and His378), arginines (Arg412, Arg418, and Arg469), and a lysine (Lys393) were probed essential to allow pAgs binding as they provide a highly positive charged environment complementary to the negative charge of the pyrophosphate moiety of pAgs. By contrast, in the B30.2 domain of BTN3A3, a single amino acid change in the position 351 from histidine (in BTN3A1) to arginine (in BTN3A3) prevents the binding of pAgs to the surface pocket and, thus, impedes the subsequent conformational changes that, ultimately, will achieve the effective activation of $\mathrm{V} \gamma 9 \mathrm{~V} \delta 2 \mathrm{~T}$ cells (51).

As we have seen above, the BTN3A2 isoform lacks the B30.2 intracellular domain, reason why this receptor might be unable to activate $\mathrm{V} \gamma 9 \mathrm{~V} \delta 2-\mathrm{T}$ cells upon pAgs intracellular accumulation (Figure 1). Surprisingly, several reports highlighted the importance of BTN3A2 and BTN3A3 expression in the activation of $\mathrm{V} \gamma 9 \mathrm{~V} \delta 2 \mathrm{~T}$ cells against their targets. Indeed, BTN3A1, A2, and $\mathrm{A} 3 \mathrm{KD} / \mathrm{KO}$ cell lines were unable to activate $\mathrm{V} \gamma 9 \mathrm{~V} \delta 2-\mathrm{T}$ cells as much as their WT counterparts upon pAgs intracellular accumulation $(36,52,53)$. Recently, Vantourout et al. showed that HEK cells $\mathrm{KO}$ for BTN3A1 alone, failed to activate $\mathrm{V} \gamma 9 \mathrm{~V} \delta 2 \mathrm{~T}$ cells, even in the presence of BTN3A2 and/or BTN3A3, confirming that BTN3A1 is strictly required for $\mathrm{V} \gamma 9 \mathrm{~V} \delta 2 \mathrm{~T}$ cell activation. However, HEK cells expressing BTN3A1 but neither BTN3A2 nor BTN3A3 did not activate $\mathrm{V} \gamma 9 \mathrm{~V} \delta 2 \mathrm{~T}$ cells. This fact suggests that BTN3A2 and BTN3A3 are somehow involved in the activation mechanism of V $\gamma 9 \mathrm{~V} \delta 2 \mathrm{~T}$ cells. In 2014, Riano et al. pointed out through transductant experiments that gene(s) on Chr6 in 
addition to BTN3A1 are mandatory for PAg-mediated activation of $\mathrm{V} \gamma 9 \mathrm{~V} \delta 2 \mathrm{~T}$ cells (54).

\section{BTN3A Homo- and Heteromers}

Last published evidences shed some light to this controversy. Adams et al. showed that BTN3A1 tends to form heterodimers with BTN3A2, as well as BTN3A1 homodimers in a lesser extent, in a native cellular environment. During their experiments, the stability of BTN3A1/A2 heterodimers was higher than those of BTN3A1 homodimers. This observation suggests that BTN3A1 tends to pair with BTN3A2 in a physiological context (55). Further confirmation of BTN3A1-A2 interaction arrived in 2018. In their work, Vantourout and coworkers showed that BTN3A2 is able to complex with BTN3A1 in an IgC-dependent manner. They also achieved to co-immunoprecipitate BTN3A3 along with BTN3A1 (Figure 2). Moreover, they demonstrated that BTN3A1 was intrinsically inefficient at cell surface localization when transfected alone in a BTN3 triple KO background. Strikingly, surface expression of BTN3A1 was greatly enhanced by co-transfecting BTN3A2 or BTN3A3 with BTN3A1. Thus, BTN3A1 transfected alone largely colocalized with the endoplasmic reticulum (ER). Nevertheless, BTN3A1 showed reduced ER colocalization in cells cotransfected with BTN3A2. These findings demonstrate that BTN3A2 helps BTN3A1 to properly localize at the cell membrane, where it exerts its action (36). It should also be noted that in their functional assays, double BTN3A2/A3 KO cells were unable to activate V $\gamma 9 \mathrm{~V} \delta 2 \mathrm{~T}$ cells, suggesting than BTN3A1 alone is unable to mediate $\mathrm{V} \gamma 9 \mathrm{~V} \delta 2$ $\mathrm{T}$ cell activation without $\mathrm{A} 2$ and/or A3. Reconstitution with either BTN3A2 or BTN3A3 in combination with BTN3A1 in BTN3 KO cells recovered the ability of cells to activate $\mathrm{V} \gamma 9 \mathrm{~V} \delta 2$ $\mathrm{T}$ cells, which means that BTN3A2 and BTN3A3 might have a redundant role in the activation process of $\mathrm{V} \gamma 9 \mathrm{~V} \delta 2 \mathrm{~T}$ cells.

Once again, similarly to the behavior of Btnll and Btnl6 in mice, as well as BTNL3 and BTNL8 described above, BTN3A1 was not efficiently expressed unless co-expressed with BTN3A2 or BTN3A3. As BTN3A2 and BTN3A1 did, Btnl1/Btnl6 coexpression reduced their colocalization with the ER. BTNL3 and BTNL8 behave similarly in order to be co-expressed at the cell membrane compartment. Strikingly, this cellular mechanism, which allows the localization of one protein to the cell membrane only when its partner protein is also expressed, seems to be conserved among several members on the BTN/BTNL families and between rodents and humans (26), even though these proteins are not predicted to be orthologs.

\section{Other BTN3A1 Interactors}

From 2015, Periplakin was also identified as an important interactor of BTN3A1 in the activation process of $\mathrm{V} \gamma 9 \mathrm{~V} \delta 2 \mathrm{~T}$ cells (52). Rhodes and coworkers demonstrated that the cytoskeletal adaptor protein Periplakin interacted with a di-leucine motif, C-terminus to the B30.2 domain of BTN3A1. However, Periplakin did not interact with BTN3A2 or BTN3A3, which do not contain the di-leucine motif. Interestingly, Periplakin depleted cells did not activate $\mathrm{V} \gamma 9 \mathrm{~V} \delta 2 \mathrm{~T}$ cells upon N-BPs treatment, suggesting a key role for Periplakin binding in the activation process of Vy9V82 T cells.
Last insights into the complex relationships governing the interactions of the actin cytoskeleton with BTN3A proteins came out in 2016, when Sebestyen et al. highlighted the critical role of RhoB small GTPase in the stabilization of BTN3A1 in the membrane, as well as its attachment to the actin cytoskeleton (56). Thus, they show that RhoB localizes mainly to the nucleus in cells resistant to V $\gamma 9 \mathrm{~V} \delta 2 \mathrm{~T}$ cells-mediated lysis and, by contrast, it preferentially localizes to the cell membrane in cells that are sensitive to V $\gamma 9 \mathrm{~V} 82-\mathrm{T}$ cells lysis. Besides that, it is also shown that the inhibition of RhoB GTPase activity on target cells with $\mathrm{C} 3$ transferase dramatically reduced the activation levels of V $\gamma 9 \mathrm{~V} \delta 2 \mathrm{TCR}+\mathrm{T}$ cells by LCL48 cells. In addition, RhoB was selectively excluded from nuclear areas in cells that are able to activate V $\gamma 9 \mathrm{~V} \delta 2 \mathrm{TCR}+\mathrm{T}$ cells, like leukemic blast of acute myeloid leukemia. Conversely, healthy stem cells from the same donor, which express RhoB mainly in the nucleus, did not activate Vy9V82 TCR+ T cells. Thus, exclusion of RhoB from the nucleus might be a cellular event which confers sensitivity to lysis by $\mathrm{V} \gamma 9 \mathrm{~V} \delta 2 \mathrm{TCR}+\mathrm{T}$ cells. Taken together, these results suggest a critical role of Periplakin and RhoB in the activation mechanism of $\mathrm{V} \gamma 9 \mathrm{~V} \delta 2 \mathrm{~T}$ cells mediated by BTN3A.

\section{BTN3A Functions in Other Immune Cells}

Activating $\gamma \delta$ T cells may not be the only function of BTN3A molecules. Some studies have highlighted the role of BTN3A in the regulation of TCR-mediated $\alpha \beta$ T cells responses. In fact we demonstrated in 2004 using the BTN3A mAb 20.1 that the molecule was largely expressed on most immune cells (48). A first study showed that the engagement of BTN3A1 expressed in co-stimulatory artificial APC, coated with CD3 mAb, through its counter-receptor expressed on CD4 T cells resulted in a decrease of CD3/CD28-dependent proliferation of CD4 T cells (57). The effect of BTN3 engagement itself on $\alpha \beta$ T cells has been confirmed by two studies. Anti-BTN3A $232.5 \mathrm{mAb}$ cross linking on CD4 and CD8 T cells induced BTN3A3 phosphorylation and inhibited CD3- and IL-2-induced T cell activation (58). Artificial APC consisting of CD3/CD28/BTN3A $20.1 \mathrm{mAb}$ coated beads enhanced co-stimulation-induced CD4 T cell proliferation and cytokine production through enhanced TCR signaling (59).

In contrast with $\mathrm{CD} 4 \mathrm{~T}$ cells, BTN3A2 is the most abundant transcript found in NK cells compared to BTN3A1 and BTN3A3 isoform, and the only one able to inhibit NK cellsinduced cytokine production. As BTN3A2 is devoid of B30.2 domain, one could postulate that BTN3A2 could be a decoy receptor. This hypothesis was further supported by the decrease of NKp30-induced cytokine production following the specific engagement of BTN3A2 but not BTN3A1 triggering on KHYG-1 transfected cells (59).

When engaged on monocytes and immature dendritic cells (iDCs) with plate-coated anti-BTN3A 19.5 or $20.1 \mathrm{mAbs}$, BTN3A protected cells from apoptosis and induced the expression of co-stimulatory and APMs. BTN3A stimulation with $\mathrm{mAb}$ synergized with toll-like receptor stimulation to increase chemokine and proinflammatory cytokine production (60). These data suggested that BTN3A subfamily could enhance and amplify inflammatory signals that are initiated by other receptors. 
On THP-1 cells [human monocytic cell line derived from acute myeloid leukemia (AML) patient], depletion of BTN3A1 inhibited the cytoplasmic nucleic acid- or virus-triggered activation of IFN- $\beta$ production, suggesting that BTN3A1 may be a novel regulator of type I IFN responses (61).

To note, cross linking of BTN3A mAbs is needed to obtain a biological effect on monocytes, iDCs, and $\alpha \beta$ T cells and this effect is the consequence of direct engagement of BTN3A expressed by responder immune cells. In marked contrast, soluble BTN3A mAbs can, in the absence of any other stimuli, sensitize the tumor cell to mediate $\mathrm{V} \gamma 9 \mathrm{~V} \delta 2 \mathrm{~T}$ cell activation.

\section{CURRENT ADVANCES ON BTN3A EXPRESSION AND REGULATION IN TUMORS}

\section{BTN3A Expression in Tumors}

BTN3A members are widely expressed in various tumors of hematological origin such as acute myeloid leukemia $(48,62)$ and solid tumors such as breast, colon $(52,63)$, ovarian (64), and more recently in gastric cancer (65) and pancreatic ductal adenocarcinoma (PDAC) (53) (Table 2). Immunohistochemical analysis of PDAC tissue microarray confirmed BTN3A expression in all the tested tumor samples, whereas BTN3A expression was either absent or barely detectable in control pancreatic tissue. Regarding the isoforms, BTN3A2 was the most expressed isoform in primary AML blasts (62). In addition, BTN3A overexpression and a dominant expression of the BTN3A2 isoform were strongly associated with a poor prognosis, in gastric cancer and PDAC $(62,65)$. This overexpression of BTN3A2 gene was associated with an increased proliferation and invasion of gastric cancer cells. Given that BTN3A2 lacks the B30.2 intracellular domain and could potentially be considered as a decoy receptor, its predominant expression in AML blasts or other tumors could constitute an immune escape mechanism to V89V82 T cell recognition. Another study showed that epithelial BTN3A expression evaluated by immunohistochemistry was significantly associated with better prognosis in high grade serous epithelial ovarian cancer patients, and correlated with higher density of infiltrating $\mathrm{T}$ cells (64). The role of BTN3A isoforms may be complex and BTN3A function in tumors could be regulated by the combinations of isoforms.

\section{BTN3A Regulation by the Tumor Microenvironment}

BTN3A is upregulated under $\mathrm{T}_{\mathrm{H}} 1$ stimulation on the surface of normal tissue namely human vein endothelial cells (48). Other studies have demonstrated that certain factors of the tumor microenvironment are able to regulate BTN3A expression (Table 3): inflammatory cytokines and hypoxia-associated mediators such as VEGF, CCL3, and IL-10 upregulate BTN3A expression in ovarian cancer (57). In a recent study, we have shown that hypoxic and metabolic stress increase BTN3A2 isoform transcript in pancreatic cell lines and patient-derived xenograft-cell lines. In addition, soluble BTN3A isoforms including soluble BTN3A1 are found in the supernatants of pancreatic cell lines and in the plasma of PDAC patients (53). The soluble isoform results from BTN3A shedding that is in part MMP-dependent, similar to that previously described for the NKG2D ligands MICA/B (66). Soluble BTN3A and sBTN3A1 were associated with a decreased overall survival in PDAC patients, and consequently could represent new attractive prognosis biomarkers. The mechanism underlying the pro-tumoral effect of sBTN3A has to be clarified. One hypothesis could be

TABLE 2 | BTN3A expression in tumors.

\begin{tabular}{|c|c|c|c|}
\hline Cancer & Method & Observations/correlation with prognosis & Reference \\
\hline Cancer cell lines & - FC & $\begin{array}{l}\text { Cell surface BTN3A expression on: } \\
\text { - T, B or monocytic leukemia cell lines } \\
\text { - Solid tumor (breast, pancreas, and ovary) cell lines }\end{array}$ & $(48)$ \\
\hline Ovarian cancer & - $\mathrm{IHC}$ & $\begin{array}{l}\text { - BTN3A2 observed on epithelial cells, some tissue cores, and stroma } \\
\text { - Correlated with CD3+ immune infiltrate } \\
\text { - High BTN3A2 associated with increased OS and disease free progression }\end{array}$ & (64) \\
\hline Breast cancer & - $I \mathrm{HC}$ & Increased BTN3A1/BTN3A3 staining in tumors sections compared to normal epithelium & (52) \\
\hline AML blasts & $\begin{array}{l}\text { - } \mathrm{FC} \\
\text { - } \text { qRT-PCR } \\
\text { - WB }\end{array}$ & $\begin{array}{l}\text { - BTN3A cell surface expression } \\
\text { - BTN3A2 most abundant isoform both at transcriptional and protein level }\end{array}$ & $(62)$ \\
\hline Colorectal cancer & $\begin{array}{l}\text { - } \text { qRT-PCR } \\
\text { - } \mathrm{WB} \\
\text { - } \mathrm{HCC}\end{array}$ & $\begin{array}{l}\text { - Three isoforms detected by WB } \\
\text { - BTN3A1 detected on epithelial cells and TAFs }\end{array}$ & (63) \\
\hline Gastric cancer & Exome array analysis & BTN3A2 associated with poor prognosis, increased proliferation and invasion of gastric cancer cell lines & (65) \\
\hline PDAC & $\begin{array}{l}\text { - } \mathrm{IHC} \\
\text { - } \mathrm{FC} \\
\text { - } \mathrm{qRT} \text {-PCR } \\
\text { - } \mathrm{WB}\end{array}$ & $\begin{array}{l}\text { - BTN3A epithelial expression in PDAC, associated with invasiveness } \\
\text { - BTN3A2 most abundant isoform both at transcriptional and protein level } \\
\text { - High BTN3A2 transcript associated with reduced OS }\end{array}$ & (53) \\
\hline
\end{tabular}

AML, acute myeloid leukemia; FC, flow cytometry; IHC, immunohistochemistry; OS, overall survival; PDAC, pancreatic ductal adenocarcinoma; qRT-PCR, real-time quantitative reverse transcription $P C R$; TAF, tumor-associated fibroblast; WB, western blot. 
TABLE 3 | Factors driving BTN3A regulation in the tumor microenvironment.

\begin{tabular}{llc}
\hline & Observations & Reference \\
\hline Inflammatory cytokines: & $\begin{array}{l}\text { BTN3A upregulation on DCs } \\
\text { and HUVECs }\end{array}$ & $(48,57)$ \\
\hline Hypox, IFN $\gamma$, CCL3, and IL-6 & BTN3A upregulation in ovarian & $(53,57)$ \\
mediators such as VEGF, & $\begin{array}{l}\text { cancer } \\
\text { PIGF, and IL-10 }\end{array}$ & $\begin{array}{l}\text { BTN3A2 transcript upregulation } \\
\text { in PDAC }\end{array}$ \\
\hline Nutrient deprivation & BTN3A2 transcript upregulation & \\
\hline Soluble BTN3A isoforms & in PDAC & \\
\hline
\end{tabular}

DCs, dendritic cells; HUVECs, human vein endothelial cells; OS, overall survival; PDAC, pancreatic ductal adenocarcinoma.

that sBTN3A may prevent V89V82 T cells from exerting their cytotoxic activity on tumor cells. This feature of soluble form is also shared with other B7 family members such as CTLA-4 and PD-L1 and has been linked to patient prognosis $(67,68)$. The soluble forms of proteins are usually generated by proteolytic cleavage of the membrane-bound form, as in the case of soluble tumor necrosis factor receptor (69) and sB7-H3 (70), or by translation of alternative spliced mRNA, as in the case of sB7-2 (71, 72), as well as sCTLA-4 $(67,68)$ and sB7-H3 (73). Increasing evidences suggest that sPD-L1 is a prognostic biomarker associated with aggressive disease in malignant tumor, such as multiple myeloma (74), diffuse large B-cell lymphoma (68), renal cell carcinoma (75), and ovarian cancer (76). In the same way, sBTN3A may provide new biomarkers easily detectable in clinical practice.

\section{Interactions Between $\gamma \delta$ T Cells and BTN/ BTNL Proteins: Therapeutic Opportunities}

$\gamma \delta \mathrm{T}$ cells, both V $\delta 1+$ and $\mathrm{V} \delta 2+$ subsets, have been shown to infiltrate a wide range of solid tumors, as well as blood cancers such as follicular lymphoma, AML Burkitt's lymphoma. Strikingly, intratumoral $\gamma \delta \mathrm{T}$ cells have emerged as the most favorable prognostic immune population among many cancer types (77). Their capacities to secrete effector cytokines and to kill tumor cells make them attractive as new immunotherapeutic targets. Lawand et al. have recently reviewed the main features of $\gamma \delta$ T cell subsets in cancer (78). However, multiple signals within the tumor microenvironment can influence the functional outcome (79). The major challenge remains thus to determine how to specifically boost the anti-tumor effects of $\gamma \delta$ T cells. Two synthetic drugs, the pAg BrHPP and N-BP Zoledronate activate $\gamma \delta \mathrm{T}$ cells in vitro and in clinical trials in vivo. However, their utility in clinics has been dampened by their bad pharmacokinetics and pharmacodynamics properties which favor their local accumulation at the bone surface and rapid renal clearance (80). New approaches have to be considered to optimize the use of $\gamma \delta \mathrm{T}$ cells in therapeutics. As reviewed here, BTN and BTNL have demonstrated a potent immunomodulatory role for certain $\gamma \delta \mathrm{T}$ cell subsets. The T-cell-stimulatory and inhibitory activity of some BTN/BTNL proteins suggests that they might be taken into account as novel targets for checkpoint inhibition (like CTLA-4, PD1, PD-L1, etc.) to potentially target $\gamma \delta \mathrm{T}$ cells (81).

\section{BTN3A and $\mathbf{V} \gamma 9 \mathrm{~V} \delta 2 \mathrm{~T}$ Cells}

BTN3A has been shown as crucial for mediating $\mathrm{V} \gamma 9 \mathrm{~V} \delta 2$ cytolytic functions against tumor cells. We have developed antiBTN3A antibodies which selectively promote an active (mAb $20.1)$ or inactive (mAb 103.2, 108.5) BTN3A conformation on the cell surface, and might broadly open the V $\gamma 9 \mathrm{~V} 82-\mathrm{T}$ cells immunotherapy field for cancer and autoimmune diseases. Notably, the $20.1 \mathrm{mAb}$ was shown to sensitize primary AML blasts and to circumvent their resistance to allogeneic $\mathrm{V} \gamma 9 \mathrm{~V} \delta 2$ $\mathrm{T}$ cells lysis. This effect induced the clearance of primary leukemic blasts from the bone marrow in vivo in an NSG human AML-xenografted mouse model (62). The $20.1 \mathrm{mAb}$ was also shown to boost BTN3A-mediated V $\gamma 9 \mathrm{~V} \delta 2 \mathrm{~T}$ cells cytolytic functions against PDAC even under hypoxic conditions, overcoming this stress-related characteristic of the PDAC microenvironment (53). Harly et al. have also shown that 20.1 $\mathrm{mAb}$ induced the activation of $\mathrm{V} \gamma 9 \mathrm{~V} \delta 2 \mathrm{~T}$ cells against a wide range of tumor cell lines (47). A recent study highlighted that $20.1 \mathrm{mAb}$ differentially activates V $\gamma 9 \mathrm{~V} \delta 2$-TCR clonotypes, and that the responsiveness strongly depends on CDR3 sequences of the TCR (82).

V $\gamma 9 \mathrm{~V} \delta 2 \mathrm{~T}$ cells were also shown to be able to kill colorectal cancer cell lines exposed to Zoledronate, this effect being partly related to $\mathrm{BTN} 3 \mathrm{~A} 1$ expression and its cellular re-distribution, in the membrane and cytoskeleton-associated fraction (63). Cross linking of BTN3A on glioblastoma-derived cell lines increased IFN- $\gamma$ secretion by $\mathrm{V} \gamma 9 \mathrm{~V} \delta 2 \mathrm{~T}$ cells (83).

As discussed above, BTN3A2 was the most expressed paralog along the BTN3A proteins in several AML (62), PDAC cell lines and primary tumors (53), and gastric cancer (65). Interestingly, the 20.1 antibody stands out for its capacity to stimulate V $\gamma 9 \mathrm{~V} \delta 2$ $\mathrm{T}$ cells independently on the predominant BTN3A paralog expressed at the cell membrane. Hence, the dominant expression of BTN3A2 isoform in tumors do not preclude the triggering of BTN3A molecules by the agonist $20.1 \mathrm{mAb}$ and the effective activation of $\mathrm{V} \gamma 9 \mathrm{~V} \delta 2 \mathrm{~T}$ cells. This effect of priming and sensitization of tumor cells to killing by $\mathrm{V} \gamma 9 \mathrm{~V} \delta 2 \mathrm{~T}$ cells would be a first therapeutic approach. We have also shown that soluble BTN3A are increased in the plasma of PDAC patients and could potentially interfere with the tumor killing activity of effector cells. Development of antibodies to mop-up soluble BTN3A could thus be another strategy.

Therefore, agonistic anti-BTN3A antibodies might represent a novel therapeutic opportunity to treat cancer. Conversely, humanized inhibitory anti-BTN3A antibodies might be taken into account as immunosuppressive drugs for the treatment of autoimmune diseases genetically associated with BTN3A, like rheumatoid arthritis or schizophrenia (84).

Oppositely, patients with ulcerative colitis (UC) showed downregulation of BTN1A1, BTN2A2, BTN3A2, and BTN3A3 levels compared to healthy controls (85). This result might be explained by the fact that BTN3A proteins trigger opposite cell responses in $\mathrm{V} \gamma 9 \mathrm{~V} \delta 2 \mathrm{~T}$ cells (co-activation) and conventional T lymphocytes (co-inhibition) $(86,87)$. For example, BTN3A 
expression levels, upregulated by tumor microenvironment signals in ovarian cancer, have been suggested to contribute to immune evasion by dampening the activity of infiltrating T cells (57). However, BTN3A2 has been shown to be associated with a good prognosis in patients with ovarian cancer, associated with an increased infiltrate of CD4+ T cells (64). Unfortunately, Vy9V82 T cell infiltrate was not assessed in this study. We can postulate that BTN3A2 would mediate other effects in other type of immune cells. As an example, a co-stimulatory role has been demonstrated for BTN3A in $\alpha \beta$ T cells that could explain different functions depending on the cellular type engaged and the tumor context. BTN3A2 promoter and ORF were related also to gastric cancer (65) and type I diabetes (88), respectively. Besides that, Gene-Based Association Analysis revealed BTN3A3 associations with rheumatoid arthritis, lower risk of relapse in ovarian cancer (89), and so on. Aberrant BTN3A3 methylation patterns were also observed on bipolar disorder and schizophrenia (90). Meta-analysis of GWAS Data also related BTN3A2 and BTN3A1 with schizophrenia susceptibility (91).

\section{Other BTN/BTNL Proteins}

The recently described role of BTNL3 and BTNL8 in the homing and maintenance of a semi activated state on $\mathrm{V} \gamma 4+\gamma \delta$ $\mathrm{T}$ cells in the human gut might be relevant for the onset of gut autoimmune diseases like UC and inflammatory bowel disease (85). Conversely, it was observed a downregulation of BTNL2, BTNL3, BTNL8, and BTNL9 mRNA in colon tumors, suggesting a co-stimulatory role for BTNL3/BTNL8 (85). Thus, the modulation of the activation signal coming from BTNL3/BTNL8 to

\section{REFERENCES}

1. Groh V, Porcelli S, Fabbi M, Lanier LL, Picker LJ, Anderson T, et al. Human lymphocytes bearing $\mathrm{T}$ cell receptor gamma/delta are phenotypically diverse and evenly distributed throughout the lymphoid system. J Exp Med (1989) 169:1277-94. doi:10.1084/jem.169.4.1277

2. Parker CM, Groh V, Band H, Porcelli SA, Morita C, Fabbi M, et al. Evidence for extrathymic changes in the $\mathrm{T}$ cell receptor gamma/delta repertoire. J Exp Med (1990) 171:1597-612. doi:10.1084/jem.171.5.1597

3. Itohara S, Farr AG, Lafaille JJ, Bonneville M, Takagaki Y, Haas W, et al. Homing of a gamma delta thymocyte subset with homogeneous T-cell receptors to mucosal epithelia. Nature (1990) 343:754-7. doi:10.1038/343754a0

4. Goodman T, Lefrancois L. Intraepithelial lymphocytes. Anatomical site, not $\mathrm{T}$ cell receptor form, dictates phenotype and function. J Exp Med (1989) 170:1569-81. doi:10.1084/jem.170.5.1569

5. Cai Y, Shen X, Ding C, Qi C, Li K, Li X, et al. Pivotal role of dermal IL-17producing gammadelta $\mathrm{T}$ cells in skin inflammation. Immunity (2011) 35:596-610. doi:10.1016/j.immuni.2011.08.001

6. Gray EE, Suzuki K, Cyster JG. Cutting edge: identification of a motile IL-17producing gammadelta $\mathrm{T}$ cell population in the dermis. J Immunol (2011) 186:6091-5. doi:10.4049/jimmunol.1100427

7. Porcelli S, Brenner MB, Band H. Biology of the human gamma delta T-cell receptor. Immunol Rev (1991) 120:137-83. doi:10.1111/j.1600-065X.1991. tb00591.x

8. Chien YH, Meyer C, Bonneville M. gammadelta T cells: first line of defense and beyond. Annu Rev Immunol (2014) 32:121-55. doi:10.1146/annurevimmunol-032713-120216

9. Holtmeier W, Pfander M, Hennemann A, Zollner TM, Kaufmann R, Caspary WF. The TCR-delta repertoire in normal human skin is restricted and distinct from the TCR-delta repertoire in the peripheral blood. J Invest Dermatol (2001) 116:275-80. doi:10.1046/j.1523-1747.2001.01250.x
$\mathrm{V} \gamma 4+\gamma \delta \mathrm{T}$ cells might be a useful approach to treat both diseases in the future.

\section{CONCLUDING REMARKS}

Recent studies have highlighted the expression of BTN3A in tumors and its correlation with patient prognosis. Notably, in vitro as well as in vivo experiments have opened new perspectives in V $\gamma 9 \mathrm{~V} \delta 2 \mathrm{~T}$ cell-based immunotherapies and shown the potential of agonists BTN3A mAbs toward enhancing $\mathrm{V} \gamma 9 \mathrm{~V} \delta 2$ $\mathrm{T}$ cell anti-tumor functions. In addition, sBTN3A may play significant role in tumor pathogenesis, immune responses, and prediction. The modulation of other BTN/BTNL molecules such as BTNL3/BTNL8 seems also of interest in other pathologies such as colon tumors or autoimmune diseases. Targeting BTN/ BTNL could thus represent an attractive strategy, alone or in combination with current therapies (i.e., pAgs and monoclonal antibodies targeting immune-checkpoint).

\section{AUTHOR CONTRIBUTIONS}

JL-B, $\mathrm{AB}$, and $\mathrm{CP}$ wrote/revised the manuscript. DO supervised/ revised the manuscript. JL- $\mathrm{B}, \mathrm{AB}$, and $\mathrm{CP}$ contributed equally to this work.

\section{ACKNOWLEDGMENTS}

JL-B is supported by a $\mathrm{PhD}$ fellowship from La Ligue contre le Cancer. DO team is labeled equipe FRM DEQ20180339209.

10. Bonneville M, O’brien RL, Born WK. Gammadelta T cell effector functions: a blend of innate programming and acquired plasticity. Nat Rev Immunol (2010) 10:467-78. doi:10.1038/nri2781

11. Hinz T, Wesch D, Halary F, Marx S, Choudhary A, Arden B, et al. Identification of the complete expressed human TCR V gamma repertoire by flow cytometry. Int Immunol (1997) 9:1065-72. doi:10.1093/intimm/9.8.1065

12. Wu YL, Ding YP, Tanaka Y, Shen LW, Wei CH, Minato N, et al. gammadelta $\mathrm{T}$ cells and their potential for immunotherapy. Int J Biol Sci (2014) 10: 119-35. doi:10.7150/ijbs.7823

13. Wang L, Xu M, Wang C, Zhu L, Hu J, Chen S, et al. The feature of distribution and clonality of TCR gamma/delta subfamilies $\mathrm{T}$ cells in patients with B-cell non-Hodgkin lymphoma. J Immunol Res (2014) 2014:241246. doi:10.1155/2014/241246

14. Hayday AC. [gamma][delta] cells: a right time and a right place for a conserved third way of protection. Annu Rev Immunol (2000) 18:975-1026. doi:10.1146/ annurev.immunol.18.1.975

15. Macleod AS, Havran WL. Functions of skin-resident gammadelta T cells. Cell Mol Life Sci (2011) 68:2399-408. doi:10.1007/s00018-011-0702-x

16. Li H, Luo K, Pauza CD. TNF-alpha is a positive regulatory factor for human Vgamma2 Vdelta2 T cells. J Immunol (2008) 181:7131-7. doi:10.4049/ jimmunol.181.10.7131

17. Van Den Broek MF, Muller U, Huang S, Zinkernagel RM, Aguet M. Immune defence in mice lacking type I and/or type II interferon receptors. Immunol Rev (1995) 148:5-18. doi:10.1111/j.1600-065X.1995.tb00090.x

18. Rhodes DA, Stammers M, Malcherek G, Beck S, Trowsdale J. The cluster of BTN genes in the extended major histocompatibility complex. Genomics (2001) 71:351-62. doi:10.1006/geno.2000.6406

19. Turchinovich G, Hayday AC. Skint-1 identifies a common molecular mechanism for the development of interferon-gamma-secreting versus interleukin-17-secreting gammadelta T cells. Immunity (2011) 35:59-68. doi:10.1016/j.immuni.2011.04.018 
20. Malcherek G, Mayr L, Roda-Navarro P, Rhodes D, Miller N, Trowsdale J. The B7 homolog butyrophilin BTN2A1 is a novel ligand for DC-SIGN. J Immunol (2007) 179:3804-11. doi:10.4049/jimmunol.179.6.3804

21. Robenek H, Hofnagel O, Buers I, Lorkowski S, Schnoor M, Robenek MJ, et al. Butyrophilin controls milk fat globule secretion. Proc Natl Acad Sci U S A (2006) 103:10385-90. doi:10.1073/pnas.0600795103

22. Nguyen T, Liu XK, Zhang Y, Dong C. BTNL2, a butyrophilin-like molecule that functions to inhibit T cell activation. J Immunol (2006) 176:7354-60. doi:10.4049/jimmunol.176.12.7354

23. Arnett HA, Escobar SS, Gonzalez-Suarez E, Budelsky AL, Steffen LA, Boiani N, et al. BTNL2, a butyrophilin/B7-like molecule, is a negative costimulatory molecule modulated in intestinal inflammation. J Immunol (2007) 178:1523-33. doi:10.4049/jimmunol.178.3.1523

24. Yamazaki T, Goya I, Graf D, Craig S, Martin-Orozco N, Dong C. A butyrophilin family member critically inhibits T cell activation. J Immunol (2010) 185:5907-14. doi:10.4049/jimmunol.1000835

25. Bas A, Swamy M, Abeler-Dorner L, Williams G, Pang DJ, Barbee SD, et al. Butyrophilin-like 1 encodes an enterocyte protein that selectively regulates functional interactions with T lymphocytes. Proc Natl Acad Sci U S A (2011) 108:4376-81. doi:10.1073/pnas.1010647108

26. Di Marco Barros R, Roberts NA, Dart RJ, Vantourout P, Jandke A, Nussbaumer O, et al. Epithelia use butyrophilin-like molecules to shape organ-specific gammadelta T cell compartments. Cell (2016) 167:203-218.e217. doi:10.1016/j. cell.2016.08.030

27. Boyden LM, Lewis JM, Barbee SD, Bas A, Girardi M, Hayday AC, et al. Skint1, the prototype of a newly identified immunoglobulin superfamily gene cluster, positively selects epidermal gammadelta T cells. Nat Genet (2008) 40:656-62. doi:10.1038/ng.108

28. Barbee SD, Woodward MJ, Turchinovich G, Mention JJ, Lewis JM, Boyden LM, et al. Skint- 1 is a highly specific, unique selecting component for epidermal T cells. Proc Natl Acad Sci U S A (2011) 108:3330-5. doi:10.1073/pnas. 1010890108

29. Adams EJ, Gu S, Luoma AM. Human gamma delta T cells: evolution and ligand recognition. Cell Immunol (2015) 296:31-40. doi:10.1016/j.cellimm.2015. 04.008

30. Rhodes DA, Reith W, Trowsdale J. Regulation of Immunity by butyrophilins. Annu Rev Immunol (2016) 34:151-72. doi:10.1146/annurev-immunol-041015055435

31. Lewis JM, Girardi M, Roberts SJ, Barbee SD, Hayday AC, Tigelaar RE. Selection of the cutaneous intraepithelial gammadelta $+\mathrm{T}$ cell repertoire by a thymic stromal determinant. Nat Immunol (2006) 7:843-50. doi:10.1038/ nil363

32. Wencker M, Turchinovich G, Di Marco Barros R, Deban L, Jandke A, Cope A, et al. Innate-like $\mathrm{T}$ cells straddle innate and adaptive immunity by altering antigen-receptor responsiveness. Nat Immunol (2014) 15:80-7. doi: $10.1038 /$ ni.2773

33. Chodaczek G, Papanna V, Zal MA, Zal T. Body-barrier surveillance by epidermal gammadelta TCRs. Nat Immunol (2012) 13:272-82. doi:10.1038/ ni0612-621d

34. Komori HK, Witherden DA, Kelly R, Sendaydiego K, Jameson JM, Teyton L, et al. Cutting edge: dendritic epidermal gammadelta $\mathrm{T}$ cell ligands are rapidly and locally expressed by keratinocytes following cutaneous wounding. J Immunol (2012) 188:2972-6. doi:10.4049/jimmunol.1100887

35. Lebrero-Fernandez C, Bergstrom JH, Pelaseyed T, Bas-Forsberg A. Murine butyrophilin-like 1 and Btnl6 form heteromeric complexes in small intestinal epithelial cells and promote proliferation of local T lymphocytes. Front Immunol (2016) 7:1. doi:10.3389/fimmu.2016.00001

36. Vantourout P, Laing A, Woodward MJ, Zlatareva I, Apolonia L, Jones AW, et al. Heteromeric interactions regulate butyrophilin (BTN) and BTN-like molecules governing gammadelta T cell biology. Proc Natl Acad Sci U S A (2018) 115:1039-44. doi:10.1073/pnas.1701237115

37. Karunakaran MM, Gobel TW, Starick L, Walter L, Herrmann T. Vgamma9 and Vdelta2 $\mathrm{T}$ cell antigen receptor genes and butyrophilin 3 (BTN3) emerged with placental mammals and are concomitantly preserved in selected species like alpaca (Vicugna pacos). Immunogenetics (2014) 66:243-54. doi:10.1007/s00251-014-0763-8

38. Bukowski JF, Morita CT, Tanaka Y, Bloom BR, Brenner MB, Band H. V gamma $2 \mathrm{~V}$ delta 2 TCR-dependent recognition of non-peptide antigens and Daudi cells analyzed by TCR gene transfer. J Immunol (1995) 154:998-1006.
39. Gober HJ, Kistowska M, Angman L, Jeno P, Mori L, De Libero G. Human $\mathrm{T}$ cell receptor gammadelta cells recognize endogenous mevalonate metabolites in tumor cells. J Exp Med (2003) 197:163-8. doi:10.1084/jem.20021500

40. Nishio N, Fujita M, Tanaka Y, Maki H, Zhang R, Hirosawa T, et al. Zoledronate sensitizes neuroblastoma-derived tumor-initiating cells to cytolysis mediated by human gammadelta T cells. J Immunother (2012) 35:598-606. doi:10.1097/ CJI.0b013e31826a745a

41. Idrees AS, Sugie T, Inoue C, Murata-Hirai K, Okamura H, Morita CT, et al. Comparison of gammadelta $\mathrm{T}$ cell responses and farnesyl diphosphate synthase inhibition in tumor cells pretreated with zoledronic acid. Cancer Sci (2013) 104:536-42. doi:10.1111/cas.12124

42. Boedec A, Sicard H, Dessolin J, Herbette G, Ingoure S, Raymond C, et al. Synthesis and biological activity of phosphonate analogues and geometric isomers of the highly potent phosphoantigen (E)-1-hydroxy-2-methylbut2-enyl 4-diphosphate. J Med Chem (2008) 51:1747-54. doi:10.1021/ jm701101g

43. Lang F, Peyrat MA, Constant P, Davodeau F, David-Ameline J, Poquet Y, et al. Early activation of human $\mathrm{V}$ gamma $9 \mathrm{~V}$ delta $2 \mathrm{~T}$ cell broad cytotoxicity and TNF production by nonpeptidic mycobacterial ligands. J Immunol (1995) 154:5986-94.

44. Hao J, Wu X, Xia S, Li Z, Wen T, Zhao N, et al. Current progress in gammadelta T-cell biology. Cell Mol Immunol (2010) 7:409-13. doi:10.1038/cmi. 2010.50

45. Wang H, Lee HK, Bukowski JF, Li H, Mariuzza RA, Chen ZW, et al. Conservation of nonpeptide antigen recognition by rhesus monkey $\mathrm{V}$ gamma $2 \mathrm{~V}$ delta $2 \mathrm{~T}$ cells. J Immunol (2003) 170:3696-706. doi:10.4049/jimmunol. 170.7 .3696

46. Bukowski JF, Morita CT, Band H, Brenner MB. Crucial role of TCR gamma chain junctional region in prenyl pyrophosphate antigen recognition by gamma delta T cells. J Immunol (1998) 161:286-93.

47. Harly C, Guillaume Y, Nedellec S, Peigne CM, Monkkonen H, Monkkonen J, et al. Key implication of CD277/butyrophilin-3 (BTN3A) in cellular stress sensing by a major human gammadelta T-cell subset. Blood (2012) 120: 2269-79. doi:10.1182/blood-2012-05-430470

48. Compte E, Pontarotti P, Collette Y, Lopez M, Olive D. Frontline: characterization of BT3 molecules belonging to the B7 family expressed on immune cells. Eur J Immunol (2004) 34:2089-99. doi:10.1002/eji.200425227

49. Palakodeti A, Sandstrom A, Sundaresan L, Harly C, Nedellec S, Olive D, et al. The Molecular Basis for Modulation of Human V $\gamma 9 \mathrm{~V} \delta 2 \mathrm{~T}$ Cell Responses by CD277/Butyrophilin-3 (BTN3A)-specific Antibodies. J Biol Chem (2012) 287:32780-90. doi:10.1074/jbc.M112.384354

50. Vavassori S, Kumar A, Wan GS, Ramanjaneyulu GS, Cavallari M, El Daker S, et al. Butyrophilin 3A1 binds phosphorylated antigens and stimulates human gammadelta T cells. Nat Immunol (2013) 14:908-16. doi:10.1038/ni.2665

51. Sandstrom A, Peigne CM, Leger A, Crooks JE, Konczak F, Gesnel MC, et al. The intracellular B30.2 domain of butyrophilin 3A1 binds phosphoantigens to mediate activation of human Vgamma9Vdelta2 T cells. Immunity (2014) 40(4):490-500. doi:10.1016/j.immuni.2014.03.003

52. Rhodes DA, Chen HC, Price AJ, Keeble AH, Davey MS, James LC, et al. Activation of human gammadelta T cells by cytosolic interactions of BTN3A1 with soluble phosphoantigens and the cytoskeletal adaptor periplakin. J Immunol (2015) 194:2390-8. doi:10.4049/jimmunol.1401064

53. Benyamine A, Loncle C, Foucher E, Blazquez JL, Castanier C, Chrétien AS, et al. BTN3A is a prognosis marker and a promising target for $\mathrm{V} \gamma 9 \mathrm{~V} \delta 2 \mathrm{~T}$ cells based-immunotherapy in pancreatic ductal adenocarcinoma (PDAC). Oncoimmunology (2017) 7(1):e1372080. doi:10.1080/2162402X.2017.1372080

54. Riano F, Karunakaran MM, Starick L, Li J, Scholz CJ, Kunzmann V, et al. Vgamma9Vdelta2 TCR-activation by phosphorylated antigens requires butyrophilin $3 \mathrm{~A} 1$ (BTN3A1) and additional genes on human chromosome 6. Eur J Immunol (2014) 44:2571-6. doi:10.1002/eji.201444712

55. Gu S, Sachleben JR, Boughter CT, Nawrocka WI, Borowska MT, Tarrasch JT, et al. Phosphoantigen-induced conformational change of butyrophilin 3A1 (BTN3A1) and its implication on Vgamma9Vdelta2 T cell activation. Proc Natl Acad Sci U S A (2017) 114:E7311-20. doi:10.1073/pnas.1707547114

56. Sebestyen Z, Scheper W, Vyborova A, Gu S, Rychnavska Z, Schiffler M, et al. RhoB mediates phosphoantigen recognition by Vgamma9Vdelta2 $\mathrm{T}$ cell receptor. Cell Rep (2016) 15:1973-85. doi:10.1016/j.celrep.2016.04.081

57. Cubillos-Ruiz JR, Martinez D, Scarlett UK, Rutkowski MR, Nesbeth YC, Camposeco-Jacobs AL, et al. CD277 is a negative co-stimulatory molecule 
universally expressed by ovarian cancer microenvironmental cells. Oncotarget (2010) 1:329-38. doi:10.18632/oncotarget.165

58. Yamashiro H, Yoshizaki S, Tadaki T, Egawa K, Seo N. Stimulation of human butyrophilin 3 molecules results in negative regulation of cellular immunity. J Leukoc Biol (2010) 88:757-67. doi:10.1189/jlb.0309156

59. Messal N, Mamessier E, Sylvain A, Celis-Gutierrez J, Thibult ML, Chetaille B, et al. Differential role for CD277 as a co-regulator of the immune signal in $\mathrm{T}$ and NK cells. Eur J Immunol (2011) 41:3443-54. doi:10.1002/eji. 201141404

60. Simone R, Barbarat B, Rabellino A, Icardi G, Bagnasco M, Pesce G, et al. Ligation of the BT3 molecules, members of the B7 family, enhance the proinflammatory responses of human monocytes and monocyte-derived dendritic cells. Mol Immunol (2010) 48:109-18. doi:10.1016/j.molimm.2010. 09.005

61. Seo M, Lee SO, Kim JH, Hong Y, Kim S, Kim Y, et al. MAP4-regulated dynein-dependent trafficking of BTN3A1 controls the TBK1-IRF3 signaling axis. Proc Natl Acad Sci U S A (2016) 113:14390-5. doi:10.1073/ pnas. 1615287113

62. Benyamine A, Le Roy A, Mamessier E, Gertner-Dardenne J, Castanier C, Orlanducci F, et al. BTN3A molecules considerably improve Vgamma9Vdelta2T cells-based immunotherapy in acute myeloid leukemia. Oncoimmunology (2016) 5:e1146843. doi:10.1080/2162402X.2016.1146843

63. Zocchi MR, Costa D, Vene R, Tosetti F, Ferrari N, Minghelli S, et al. Zoledronate can induce colorectal cancer microenvironment expressing BTN3A1 to stimulate effector gammadelta T cells with antitumor activity. Oncoimmunology (2017) 6:e1278099. doi:10.1080/2162402X.2016.1278099

64. Le Page C, Marineau A, Bonza PK, Rahimi K, Cyr L, Labouba I, et al. BTN3A2 expression in epithelial ovarian cancer is associated with higher tumor infiltrating T cells and a better prognosis. PLoS One (2012) 7:e38541. doi:10.1371/ journal.pone. 0038541

65. Zhu M, Yan C, Ren C, Huang X, Zhu X, Gu H, et al. Exome array analysis identifies variants in SPOCD1 and BTN3A2 that affect risk for gastric cancer. Gastroenterology (2017) 152:2011-21. doi:10.1053/j.gastro.2017.02.017

66. Marten A, Von Lilienfeld-Toal M, Buchler MW, Schmidt J. Soluble MIC is elevated in the serum of patients with pancreatic carcinoma diminishing gammadelta T cell cytotoxicity. Int J Cancer (2006) 119:2359-65. doi:10.1002/ ijc. 22186

67. Ward FJ, Dahal LN, Wijesekera SK, Abdul-Jawad SK, Kaewarpai T, Xu H, et al. The soluble isoform of CTLA-4 as a regulator of T-cell responses. Eur J Immunol (2013) 43:1274-85. doi:10.1002/eji.201242529

68. Rossille D, Gressier M, Damotte D, Maucort-Boulch D, Pangault C, Semana G, et al. High level of soluble programmed cell death ligand 1 in blood impacts overall survival in aggressive diffuse large B-cell lymphoma: results from a French multicenter clinical trial. Leukemia (2014) 28:2367-75. doi:10.1038/ leu.2014.137

69. Xanthoulea S, Pasparakis M, Kousteni S, Brakebusch C, Wallach D, Bauer J, et al. Tumor necrosis factor (TNF) receptor shedding controls thresholds of innate immune activation that balance opposing TNF functions in infectious and inflammatory diseases. JExp Med (2004) 200:367-76. doi:10.1084/ jem. 20040435

70. Zhang G, Hou J, Shi J, Yu G, Lu B, Zhang X. Soluble CD276 (B7-H3) is released from monocytes, dendritic cells and activated $\mathrm{T}$ cells and is detectable in normal human serum. Immunology (2008) 123:538-46. doi:10.1111/j. 1365-2567.2007.02723.x

71. Jeannin P, Magistrelli G, Aubry JP, Caron G, Gauchat JF, Renno T, et al. Soluble CD86 is a costimulatory molecule for human T lymphocytes. Immunity (2000) 13:303-12. doi:10.1016/S1074-7613(00)00030-3

72. Kapsogeorgou EK, Moutsopoulos HM, Manoussakis MN. A novel B7-2 (CD86) splice variant with a putative negative regulatory role. J Immunol (2008) 180:3815-23. doi:10.4049/jimmunol.180.6.3815

73. Chen W, Liu P, Wang Y, Nie W, Li Z, Xu W, et al. Characterization of a soluble B7-H3 (sB7-H3) spliced from the intron and analysis of sB7-H3 in the sera of patients with hepatocellular carcinoma. PLoS One (2013) 8:e76965. doi:10.1371/journal.pone. 0076965

74. Wang L, Wang $\mathrm{H}$, Chen $\mathrm{H}$, Wang WD, Chen XQ, Geng QR, et al. Serum levels of soluble programmed death ligand 1 predict treatment response and progression free survival in multiple myeloma. Oncotarget (2015) 6:41228-36. doi:10.18632/oncotarget.5682
75. Frigola X, Inman BA, Lohse CM, Krco CJ, Cheville JC, Thompson RH, et al. Identification of a soluble form of $\mathrm{B} 7-\mathrm{H} 1$ that retains immunosuppressive activity and is associated with aggressive renal cell carcinoma. Clin Cancer Res (2011) 17:1915-23. doi:10.1158/1078-0432.CCR-10-0250

76. Chatterjee J, Dai W, Aziz NHA, Teo PY, Wahba J, Phelps DL, et al. Clinical use of programmed cell death-1 and its ligand expression as discriminatory and predictive markers in ovarian cancer. Clin Cancer Res (2017) 23(13): 3453-60. doi:10.1158/1078-0432.CCR-16-2366

77. Gentles AJ, Newman AM, Liu CL, Bratman SV, Feng W, Kim D, et al. The prognostic landscape of genes and infiltrating immune cells across human cancers. Nat Med (2015) 21:938-45. doi:10.1038/nm.3909

78. Lawand M, Dechanet-Merville J, Dieu-Nosjean MC. Key features of gamma-delta T-cell subsets in human diseases and their immunotherapeutic implications. Front Immunol (2017) 8:761. doi:10.3389/fimmu.2017.00761

79. Lafont V, Sanchez F, Laprevotte E, Michaud HA, Gros L, Eliaou JF, et al. Plasticity of gammadelta T cells: impact on the anti-tumor response. Front Immunol (2014) 5:622. doi:10.3389/fimmu.2014.00622

80. Benzaid I, Monkkonen H, Stresing V, Bonnelye E, Green J, Monkkonen J, et al. High phosphoantigen levels in bisphosphonate-treated human breast tumors promote Vgamma9Vdelta2 T-cell chemotaxis and cytotoxicity in vivo. Cancer Res (2011) 71:4562-72. doi:10.1158/0008-5472.CAN-10-3862

81. Menon S, Shin S, Dy G. Advances in cancer immunotherapy in solid tumors. Cancers (Basel) (2016) 8:E106. doi:10.3390/cancers8120106

82. Starick L, Riano F, Karunakaran MM, Kunzmann V, Li J, Kreiss M, et al. Butyrophilin 3A (BTN3A, CD277)-specific antibody 20.1 differentially activates Vgamma9Vdelta2 TCR clonotypes and interferes with phosphoantigen activation. Eur J Immunol (2017) 47:982-92. doi:10.1002/eji.201646818

83. Marcu-Malina V, Garelick D, Peshes-Yeloz N, Wohl A, Zach L, Nagar M, et al. Peripheral blood-derived, gamma9delta2 $\mathrm{t}$ cell-enriched cell lines from glioblastoma multiforme patients exert anti-tumoral effects in vitro. J Biol Regul Homeost Agents (2016) 30:17-30.

84. Paul S, Shilpi S, Lal G. Role of gamma-delta (gammadelta) T cells in autoimmunity. J Leukoc Biol (2015) 97:259-71. doi:10.1189/jlb.3RU0914-443R

85. Lebrero-Fernandez C, Wenzel UA, Akeus P, Wang Y, Strid H, Simren M, et al. Altered expression of butyrophilin (BTN) and BTN-like (BTNL) genes in intestinal inflammation and colon cancer. Immun Inflamm Dis (2016) 4:191-200. doi:10.1002/iid3.105

86. Gao Y, Williams AP. Role of innate T cells in anti-bacterial immunity. Front Immunol (2015) 6:302. doi:10.3389/fimmu.2015.00302

87. Durek P, Nordstrom K, Gasparoni G, Salhab A, Kressler C, De Almeida M, et al. Epigenomic profiling of human $\mathrm{CD} 4(+) \mathrm{T}$ cells supports a linear differentiation model and highlights molecular regulators of memory development. Immunity (2016) 45:1148-61. doi:10.1016/j.immuni.2016.10.022

88. Viken MK, Blomhoff A, Olsson M, Akselsen HE, Pociot F, Nerup J, et al. Reproducible association with type 1 diabetes in the extended class I region of the major histocompatibility complex. Genes Immun (2009) 10:323-33. doi:10.1038/gene.2009.13

89. Peedicayil A, Vierkant RA, Hartmann LC, Fridley BL, Fredericksen ZS, White KL, et al. Risk of ovarian cancer and inherited variants in relapseassociated genes. PLoS One (2010) 5:e8884. doi:10.1371/journal.pone.0008884

90. Chen C, Zhang C, Cheng L, Reilly JL, Bishop JR, Sweeney JA, et al. Correlation between DNA methylation and gene expression in the brains of patients with bipolar disorder and schizophrenia. Bipolar Disord (2014) 16:790-9. doi:10.1111/bdi.12255

91. Gejman PV, Sanders AR, Duan J. The role of genetics in the etiology of schizophrenia. Psychiatr Clin North Am (2010) 33:35-66. doi:10.1016/j. psc.2009.12.003

Conflict of Interest Statement: DO is the cofounder and shareholder of Imcheck Therapeutics. No potential conflicts of interest were disclosed by the remaining authors.

Copyright (c) 2018 Blazquez, Benyamine, Pasero and Olive. This is an open-access article distributed under the terms of the Creative Commons Attribution License (CC BY). The use, distribution or reproduction in other forums is permitted, provided the original author(s) and the copyright owner(s) are credited and that the original publication in this journal is cited, in accordance with accepted academic practice. No use, distribution or reproduction is permitted which does not comply with these terms. 